\title{
EDITORIAL
}

\section{CIENCIA, TECNOLOGÍA E INNOVACIÓN FRENTE AL PROYECTO DE RECURSOS PROVENIENTES DE REGALÍAS}

\author{
Germán Anzola Montero \\ Rector
}

La Universidad de Ciencias Aplicadas y Ambientales U.D.C.A consagra, en su Proyecto Educativo Institucional, la función investigativa, como un quehacer fundamental, en cumplimiento de las definiciones establecidas en su Misión y Visión pretendiendo, con ello, alcanzar los niveles propios de una Universidad de excelencia académica y, por qué no decirlo, en su camino por querer referenciarse a las denominadas Universidades de clase mundial. Esta es la razón que me motiva, para disertar en esta entrega de nuestra revista ACTUALIDAD \& DIVULGACIÓN CIENTÍFICA, lo que es el presente y futuro de la investigación en la U.D.C.A, frente a las políticas que, con un nuevo Gobierno, se pretende implantar e implementar, con fundamento en la mirada del nuevo Director de COLCIENCIAS y de un Proyecto sobre regalías, que podría derivar significativos recursos para el financiamiento de la Ciencia, la Tecnología y la Innovación.

Puedo afirmar que la investigación en la U.D.C.A ha correspondido a sus realidades institucionales, las cuales, no son ajenas al contexto nacional. En una primera etapa, entre 1987 y 1996, impulsamos, de manera significativa, la investigación formativa, básicamente, con los trabajos de investigación de nuestros estudiantes, en cumplimiento con una de las opciones de graduación. Esta investigación, bajo los dos recursos más importantes que teníamos para ello: el talento humano, representado en nuestros docentes investigadores y los estudiantes, inicialmente de los programas de Medicina Veterinaria y de Zootecnia, estos trabajos se incrementaron, en la medida que se desarrollaron nuevas carreras universitarias; su financiamiento, en un $100 \%$ con recursos propios, es decir, los provenientes de la matrícula de los estudiantes.

Un segundo momento, que oscila entre 1996 y 2010 correspondió, bajo la justificación del proceso de reconocimiento de Universidad, la consolidación de la investigación formativa y el fomento e impulso a la investigación, que hemos denominado, de alto nivel. Esta etapa dispuso, para su ejecución, de los recursos indicados para la primera fase y con un aporte, no muy significativo, de financiación externa, tanto a nivel de número de propuestas investigativas como del número de investigadores competitivos, a nivel de estas fuentes externas, ya sean del orden nacional o internacional. Lógicamente, los resultados de la actividad investigativa, expresada en patentes, en publicaciones científicas en revistas indexadas y en otras formas de presentar y exponer resultados, como Congresos y eventos científicos, no son suficientes para las metas que se propone el gobierno nacional, en lo que respecta a la actividad científica de las Universidades.

La pretensión de lograr la acreditación institucional y, desde luego, la acreditación y reacreditación de todos los programas académicos, nos obliga a establecer y a lograr nuevas y ambiciosas metas y objetivos, en el ámbito de las realidades de la segunda década del siglo XXI: Investigación caracterizada por su pertinencia social y científica (solución problemas de la sociedad); un número de proyectos significativos en Ciencia, Tecnología e Innovación, independientemente de la cantidad de ellos; investigación que trascienda en el desarrollo social y humano; investigación aplicada, que nos conduzca al logro y al registro de patentes, de marcas y de empresas (spin off); incremento de recursos económico-financieros, tanto del orden nacional como internacional, para el financiamiento de todo tipo de necesidades y que derivan una sólida investigación científica: Laboratorios de investigación, dotación en materiales y en equipos, formación de investigadores, movilidad nacional e internacional de investigadores, internacionalización de la investigación, participación en redes de investigación, tanto locales como externas, creación de redes en innovación, ciencia y tecnología en torno al medio ambiente, al desarrollo sustentable y sostenible, a las ciencias de la salud, al sector agropecuario.

Y estos deben ser nuestros propósitos en cumplimiento de la función investigativa: lograr contribuir, de manera 
eficiente, en la construcción de nuestro país; de una sociedad del conocimiento vinculada con los problemas reales de Colombia; de una investigación al servicio de la humanidad, mediante la apropiación y la utilización del conocimiento, para atender las necesidades que demanda su desarrollo y para la edificación de su propio futuro. La U.D.C.A, en el logro de sus metas, definitivamente, no podrá ser ajena a las políticas y al real progreso investigativo de la nación.

La demanda de carácter económico-financiero para responder a la investigación que se genera en las universidades colombianas, no corresponde a la oferta de proyectos. Otra dificultad que se identifica, concierne a las desigualdades entre las universidades, en algunos casos, por su nivel de desarrollo y, otros, por la distribución regional de las mismas. Expresa el señor Director de COLCIENCIAS, doctor Jaime Restrepo Cuartas: "Es necesario afianzar los consejos departamentales de ciencia, tecnología e innovación, estableciendo Centros de Desarrollo Tecnológico de alto nivel científico en las regiones de menor desarrollo relativo". Complementariamente, se ratifica, como se viene haciendo, desde hace muchos años, la estrategia derivada de las relaciones Universidad - Empresa Estado, alternativa para que los resultados de la investigación estén al servicio de los avances tecnológicos del país.

Así mismo, comenta el doctor Cuartas, en reciente entrevista concedida a UN Periódico (Publicación de la Universidad Nacional de Colombia, No. 138, sección Ciencia y Tecnología, domingo 10 de octubre de 2010, p. 17), cerca de las políticas que impulsará COLCIENCIAS, para favorecer el desarrollo científico del país:

- Fortalecer la estructura financiera.

- Consolidar la regionalización de Ciencia, Tecnología e Innovación.

- Disminuir diferencias entre universidades de menor desarrollo con las de mayor desarrollo.

- $\quad$ Fortalecer las relaciones: Universidad - Empresa - Estado.

- Destinar el $10 \%$ del proyecto regalías a Ciencia, Tecnología, Innovación.

- Centralizar en COLCIENCIAS todos los recursos para la investigación, asignados a Ministerios y otras instituciones del Estado.

- Definir áreas estratégicas de desarrollo por parte de los Ministerios.

- Aplicar 50 millones de dólares, de un empréstito de 500 millones, en la cualificación científica y técnica de COLCIENCIAS.
Del supuesto $10 \%$ de las regalías que pueden equivaler a 600 mil millones de pesos, en el año 2012, se destinarían estos recursos, así:

- Formar 1500 doctores por año, hoy se forman 700.

- Mejorar laboratorios y centros de investigación en infraestructura y técnicas de aplicación.

- Fomentar la creación de centros y grupos de investigación.

- Financiar el $50 \%$ de los proyectos que sean recepcionados por COLCIENCIAS, hoy en día, se financia tan solo el $6 \%$.

- Fomentar la construcción de un mayor número de empresas de base tecnológica, incubadoras de empresas, parques de emprendimiento y centros de desarrollo tecnológico.

Muy importante para la U.D.C.A saber que las líneas estratégicas de investigación a las que se destinarán mayores recursos son: las relacionadas con los sectores agrícola y pecuario, en función de la seguridad alimentaria; con el ambiente, la biodiversidad, la protección de agua y la biotecnología, y la minería y la energía.

De todos es conocido que para el año 2010, se proponía, que se contará con el $1 \%$ del PIB, para destinarlo a Ciencia, Tecnología e Innovación, meta que no se cumplió, por ausencia de la asignación correspondiente de los recursos; tan sólo se reciben el 0,16\% del PIB. Si se lograra el 10\% de las regalías, tan sólo llegaríamos al 0,5\%, es decir, que para llegar al 1\%, se requerirá de otros esfuerzos e identificación de otras fuentes de financiación.

Desde 1994, el uso de las regalías y las compensaciones producto de la explotación de los recursos naturales, se hace mediante un modelo de descentralización, donde se reconoció el derecho de los entes territoriales sobre sus recursos naturales. Este esquema ha generado dificultades que se pretenden corregir, con la presentación de un proyecto de acto legislativo (una reforma a la Constitución vigente), con miras a corregir las dificultades que el Gobierno ha identificado, como serias dificultades o limitaciones, entre las cuales, se pueden citar: corrupción y utilización indebida de estos recursos; generación de mayores desigualdades entre los entes territoriales y, en consecuencia, incremento de la pobreza y, finalmente, ausencia en la mayoría de los casos de óptima eficiencia y eficacia.

El Gobierno Nacional ha propuesto, con este proyecto de reforma, la aplicación de estos recursos para el fortalecimiento y mayor competitividad del país, en lo relativo a la implementación de zonas de frontera e impulsar y consolidar la ciencia, la tecnología y la innovación. De lógica importancia 
para las universidades colombianas, teniendo en cuenta las apreciaciones entregadas por la dirección de COLCIENCIAS.

Esta eventual determinación nos aproximaría, significativamente, a la aplicación cercana al $1 \%$ del PIB en ciencia, tecnología e innovación; de igual manera, estaría reconociendo el potencial científico de los entes territoriales, siempre sin financiación, por la intensa práctica de políticas centralistas, para nuestro país. Estas y otras consideraciones toman vigencia para el sector universitario.
Nuevas reflexiones, para unas circunstancias de cambio en el escenario que enfrenta la investigación de las universidades colombianas y, en particular la U.D.C.A, que en el contexto en sus realidades debe reflexionar sobre ella misma, para visualizar sus fortalezas y sus debilidades, para así definir las bases de su plan de mejoramiento continuo, en este caso, en el ámbito de la investigación. 